\title{
OPTIMIZATION OF TEACHING OF THE COURSE "LIFE SAFETY" TO THE STUDENTS OF THE HUMANITIES UNIVERSITIES
}

\author{
Angela Cristina Di Palma Back, $\mathrm{PhD}$ in Linguistics \\ UNESC, Criciuma, Brazil \\ Irina Kuvshinova, $\mathrm{PhD}$ in Education \\ NMSTU, Magnitogorsk, Russia
}

\begin{abstract}
The article presents the analysis of modern education at the humanities universities in Russia and abroad with the emphasis on the conditions for enhancement of teaching effectiveness of the discipline «Life Safety». The authors focus on the specifics of teaching the course «Life Safety» to students of the humanities universities, on the need to integrate scientific knowledge, both at the level of content and organization of educational process taking into account the specifics of future professional activity of students in the humanities.
\end{abstract}

Keywords: life safety, professional pedagogical training, humanities universities.

Currently, the problem of modernization of humanities students' professional pedagogical training has acquired a special significance and relevance. The interest of professional training of humanities students is growing. The first feature of modern educational systems of the USA, Japan, Western Europe is manifested in their humanistic orientation. At the turn of XX-XXI centuries the idea that fundamental principle and the criterion of efficiency of the educational institution of any type should become humanism education that is provided and the contents and methods of pedagogical influence [4]. But the larger result is achieved by the recognition of the priority of the individual student as the highest value of society.

Predicting professional school of the XXI century, scientists from different countries agree that it should meet the needs of specialists in different professional competence, and also to carry out the educational process on the principles of pedagogy of co-creation, stimulating cognitive activity of students and effectively realizing their creative potential. «In the next decade more than seven million higher education students are expected to study trans-nationally. Education abroad has become diverse (internships, summer work, field research, volunteering) and motivated by the range of goals (foreign language study, cultural enrichment, professional development)» [2, p. 104].

Modern researchers have expressed different opinions on the problem of professionalpedagogical training. So, if in the last edition of the Pedagogical encyclopedia (1966) under training 
refers to «a set of special knowledge, skills, qualities, work experience and norms of behavior that ensure the possibility of success in a certain profession; - the process of telling the students the appropriate knowledge and skills» [1]. Now in a number of publications on this issue can meet the definition of training, for example, as a system of organizational and teaching activities, ensuring the formation of the personality professional orientation knowledge, skills, abilities and professional readiness for such activity; or as a system of professional learning that is accelerated learners acquire the skills needed to perform a specific job, group of jobs. It is emphasized that it is not accompanied by an increase in the educational level of the student. According to the definitions, General professional disciplines, such as «Safety», to vocational training do not have. In addition, some authors see the discipline «Life Safety» as a mechanical grouping of data from environmental, occupational safety, emergency situations, sanitation, hygiene and other subjects, presenting them in a random order [6].

We cannot agree with this position, because we believe that the existence of knowledge and practical skills in the field of security is an important criterion for evaluating human activity in any organization. The quality ensuring the safety of people is an acute problem of mankind. Socioeconomic living conditions, increasing awareness and mental stress, the environment and labour conditions, the transition from post industrial society to the risk society, forced modern society to emphasize safety as the universal value of mankind, connected with the welfare of civilization. A special place among the problems of security is a problem of professional-pedagogical training of students to safe life and professional activity in the modern world.

In addition, the educational discipline «Life Safety», taking into account modern views, is a multifaceted object of understanding and perception of reality, which requires the integration of different strategies, areas, aspects, forms and levels of knowledge in various scientific fields and each module (discipline) contributes to the formation of certain competences through the content and organization of the educational process. The anthropocentric pedagogy «represents the human species as the most superior and rational, it teaches that the world was created in order to be dominated and governed by man» [3, p. 3].

In this regard, the main task of education is not providing some fund of knowledge, and the armament of the learners' original culture, which will allow them to find their place in life and will give the opportunity to make their own decisions. Therefore, universities need to focus not on the translation of knowledge, as it often is today, but more to pay attention to the motivation of selfeducation. This will allow in the future to overcome the objectively existing contradiction between the ever-changing demands and opportunities of the education system. Because the socio-economic Criar Educação, Criciúma, v. 6, n¹, julho/novembro 2016.- PPGE - UNESC 
and socio-political factors not only affect the growth prospects of education, but also face new challenges to all its structures.

«In the new information society we don't have time to make layer by layer to make knowledge correlated poorly with the modern environment», says French researcher P. Schaeffer, consequently, in the training necessary to move from the simple accumulation of «fast fading» of knowledge to the acquisition of skills for «further independent search, selection and application of newly acquired information» [5]. Therefore, in the international practice one of the main objectives is to teach students the methods of independent acquisition of knowledge. For example, in U.S. Universities there is an increasing tendency towards reduction of lecture time, mandatory educational classes, and more attention is paid to independent work of students (this applies more to older courses), which, according to various estimates, should be from half to two thirds of training time, at the decision of problems of optimization of educational process, based on the individualization of educational plans. Individualization of training sessions as the basis of modern educational process at multi-stage technology is the lack of strict regulation disciplines in the curriculum, so that every student has the opportunity to receive training with individual professional and educational bias.

Thus, having considered some aspects of professional-pedagogical training of studentshumanists, we came to the conclusion that in the context of the present day manifest contradiction between the need to optimize existing and actively used in practice of the professionallypedagogical preparation of students of humanities universities traditional teaching methods, on the one hand, and the need for immediate development of pedagogical practice-oriented technologies and additional modules for the successful formation of professionally oriented knowledge, abilities and skills of students of humanities universities for future professional activity; and between the level of professional requirements to professional training of students of humanities directions of universities on the one hand, on the other hand, the lack of pedagogical conditions of optimization of professional-pedagogical training of humanities students in higher professional education.

Domestic and foreign scholars [4], analyzing the situation, try to find ways out of it, predict professional school at the beginning of the XXI century. The main features of professionalpedagogical training of students of humanities should be:

- humanistic orientation, the recognition of the priority of the individual;

- the holistic approach to the learning process of the individual;

- transition of the future specialist from object position to subject position;

- the revision of the contents, forms and methods of professional training; 
- development of new technologies of professional training, reflecting the level of modern fundamental and applied sciences, differentiation and individualization, best practices, etc.

In our research, we found that professionally-pedagogical training of students of the humanities universities to secure vital will be effective if competency-activity, value-oriented and axiological approaches developed and implemented an optimization model of professionalpedagogical training of students to safe life, in which it is implemented the following set of organizational-pedagogical conditions:

- to organize training for safe life, with integration of scientific knowledge and modern level of development of sciences using the disciplines of the curriculum, both at the level of content and organization of educational process taking into account the specifics of future professional activity of students;

- to apply a structural and logical approach to organization and presentation of information in the field of life safety in order to intensify the educational process;

- to use possibilities of information and communication technologies, including the Internet education, in the process of professionally-pedagogical training of students;

- to use the method of active problem-situational analysis, case-study technologies.

We touch on some aspects of theoretical study and practical implementation of the outlined conditions. The optimization of professional-pedagogical training of students for safe life in the system of higher professional education requires the creation of fundamentally new approaches.

Training students of humanities universities in the field of life safety is based on the original principles of its implementation - consistency, scientific character, fundamentality, modularity, unity of integration and differentiation, technology, greening, etc. They define the leading purpose and the essential characteristics of learning, provide effective and qualitative functioning of the educational process for learning the content of the discipline «Life Safety» taking into account the specifics of the educational program and future professional activity of students of humanities directions of training. When developing working programs on the discipline «Life Safety» for various humanities directions of a bachelor degree are considered subjects of the curriculum on the basis of which it is possible to integrate scientific knowledge and modern level of development of science, both at the level of content and organization of the educational process. Thus the working programmes, in addition to the basic and obligatory sections, a section relating to security in the professional field. The study of this topic the students is carried out through the study 
of theoretical aspects of writing scientific articles, use the method of active problem-situation analysis, case-study technologies, and perform creative tasks in practical and internship practices.

Here is a brief description of the implementation of information and educational technologies in the context of our study. So, as educational technologies in teaching the discipline «Life Safety» using traditional and modular competency technology, as well as case-study method or a method of concrete situations. For example, when studying the "Protection of Population and Territories in Emergency Situations" technique has been used to study the development of critical thinking, the essence of which is to develop the capacity to put new questions, to develop a variety of arguments, to make independent decisions in emergency situations. This technology is realized through interactive inclusion of students in the educational process of compliance with three stages of technology implementation: the call (the actualization of subjective experience); reflection; reflection.

In the study material section on «Protection of Population and Territories in Emergency Situations», as well as the section associated with security in the future professional activity of students in the humanities used the method of active problem-situation analysis, based on learning by solving specific problems - situations (case studies). The immediate goal of the method casestudy - a joint effort of a team of students to analyze extreme or emergency situation (case) that occur when specific hazardous conditions, and to develop a practical solution; the end of the process - evaluation of the proposed algorithms and the best choice in the context of the problem. The emphasis of learning is transferred not on the acquisition of ready knowledge, and his production, co-creation of a student and a teacher. The result of the method is not only knowledge but also behavioral skills in a particular dangerous situation. The apparent advantage of the method of situational analysis is not only the acquisition of knowledge and formation of practical skills and values development of students, professional positions, attitudes, a kind of professional attitude and monopropylene, the culture of safe life.

In the process of working on the theoretical material of the section «Ensuring Safety of Professional Activities», and perform practical tasks technology is used active (context) learning. Thus there is modeling the subject and social content of professional activities, for example, future teachers - teacher action to protect children in various dangerous and emergency situations and ensure security of educational institutions.

The transfer is necessary theoretical knowledge and the formation of the basic views on the course «Life Safety» is using multimedia equipment. 
Lectures are held in the traditional form, in the form of lectures, consultations and problem lectures. The theoretical material on the problem lecture is the result of adopting the information received through the formulation of a problem and search of ways of its decision. Lectures - consultations introduction of new material accompanied by questions and discussion in search of answers to these questions. When practical exercises are teamwork and techniques. Stimulates independent work of students in preparation of homework, when solving situational tasks for practical training, in preparation for quizzes and the final certification. Classroom independent work of students on practical training is carried out under the supervision of a teacher in solving problems and performing exercises that are determined by the teacher to the student. Extracurricular independent work of students is carried out in the form of a reader with study material and assignments with consultation of the teacher.

Training students in the field of life safety in the higher education system is based on the original principles of its implementation (systemacity, scientific character, fundamentality, integration, differentiation, unity of integration and differentiation, modularity, manufacturability, greening, etc.). They define the leading purpose and the essential characteristics of learning, provide effective and qualitative functioning of the educational process for learning the content of the discipline "Life Safety" and includes the main subject concepts (knowledge), skills, as well as its role in preparing students.

Thus, the analysis of historical and pedagogical experience and modern state of professional preparing students of humanities universities to secure vital allowed to reveal, experimentally verify and to substantiate scientifically the most effective measures to further improve the efficiency of the process.

\section{References:}

1. EDUCATIONAL ENCYCLOPEDIA. In 4 V. / I.A. Kairov, F.N. Petrov. M.: Soviet Encyclopedia. V. 3. 1966. - 879 p.

2. GUSEVA L.G. Ethnopedagogy and intercultural communication in higher education / Modern developmental psychology: main trends and prospects of research : materials of the international scientific conference. Oct. 20-21, 2015. - Prague : Vědecko vydavatelské centrum «Sociosféra-

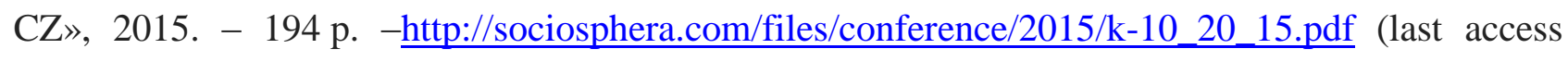
July 22, 2016) 


\section{CRIAR EDUCAÇÃO \\ Revista do Programa de Pós-Graduação em Educação - UNESC}

3. GUSEVA L.G., CAROLA C.R. Ecopedagogy in education as the liberating praxis of modern society / World of Science. 2016. http://mir-nauki.com/PDF/ 10PDMN116.pdf (last access July 22, 2016)

4. NAUMOVA A.E. New Approaches to the Professional Pedagogical Training of Students. / Yaroslavl Pedagogical Bulletin. Pedagogy and psychology. 2000, No 2. http://vestnik.yspu.org/releases/pedagoka_i_psichologiy/11_5/ (last access July 31, 2016)

5. SCHAEFFER P. Professional education in the information society. - M.: Progress, 1991. - 217 p.

6. YAKUPOV M.A., KUVSHINOVA I.A., DENISOV V.V. The problems of Teaching the Discipline «Health and Safety» to the Students of Humanities Specialties of Higher Education Institutions and the Ways of their Solution / Bulletin of the state budgetary institution «Scientific center of life» : scientific-methodical and information magazine No. 3 (25) 2015. - 141 p. / P. 90 101. http://ncbgd.tatarstan.ru/rus/file/pub/pub_353189.pdf (last access July 22, 2016)

\section{Authours:}

Irina Kuvshinova

Candidate of pedagogical sciences, Associate professor

Department of Special Education and Medical-biological disciplines

Institute of Pedagogy, Psychology and Social Work

Nosov Magnitogorsk State Technical University

Angela Cristina Di Palma Back, PhD in Linguistics.

UNESC, Criciuma, Brazil 